\title{
MULTIMODALIDADE E A CONSTRUÇÃO DA IDENTIDADE DO SEM-TERRA
}

\section{MULTIMODALITY AND THE IDENTITY CONSTRUCTION OF LANDLESS WORKERS}

Vanderlei J. Zacchi

RESUMO: O objetivo deste trabalho é analisar a maneira como o Movimento dos Trabalhadores Rurais Sem Terra (MST) utiliza os diferentes modos de produção de significado e como, nesse processo, é construída sua identidade. A análise será efetuada principalmente a partir de textos impressos, digitais e eletrônicos produzidos pelos sem-terra. Apesar de fazer bom uso das diversas habilidades pressupostas na multimodalidade, o movimento ainda se apoia fortemente no modo linguístico tanto na autorrepresentação quanto na ação social.

PALAVRAS-CHAVE: multiletramento, MST, identidade, Internet, mídia.

ABSTRACT: This paper aims at analysing the identity construction of the Landless Rural Workers Movement (MST) by making use of different modes of meaning-construction. The data provided for analysis are based especially on printed, electronic, and digital texts produced by the movement. Although the MST uses multimodal texts extensively, it still relies heavily on the linguistic mode when engaging in both self-representation and social action.

KEYWORDS: multiliteracies, landless movement, identity, Internet, media.

\footnotetext{
* Professor Assistente da Universidade Federal de Sergipe, campus de São Cristóvão, e doutor em Estudos Linguísticos e Literários em Inglês pela USP.vanderlei@ufs.br
} 



\section{INTRODUÇÃO}

A interação de diferentes técnicas e habilidades nos processos de aprendizagem e de construção de identidade tem sido objeto de um grande número de recentes estudos na área de ensino de línguas. Para além do texto escrito, aspectos visuais, digitais e sonoros passam a desempenhar papel fundamental. Da mesma maneira, leitura e escrita se mesclam com outras habilidades como a auditiva, a visual e a espacial, intensificadas pelos meios de comunicação de massa e pelas novas mídias. Essa visão está na base dos estudos sobre multiletramento e multimodalidade (BRASIL, 2006; COPE; KALANTZIS, 2000a; KRESS; VAN LEEUWEN, 2006; MENEZES DE SOUZA, 2005; MONTE MÓR, 2006). Embora muitos desses estudos tenham como referência o estudante ou usuário urbano e pertencente à classe média, não se pode ignorar o potencial de empoderamento que as novas mídias proporcionam para grupos minoritários. Além disso, assumem importância maior, habilidades já dominadas por integrantes desses grupos que não eram privilegiadas no ensino tradicional - altamente caracterizado por uma abordagem linguística - e que agora tomam novo significado. A comunicação visual, por exemplo, sempre desempenhou papel importante entre os indígenas (MENEZES DE SOUZA, 2005). Segundo Cope e Kalantzis (2000b: 5), essas habilidades são também "modos de produção de significado", pois se caracterizam como recursos semióticos em situações de comunicação e representação. 
Este trabalho se propõe a analisar a utilização dos diversos modos de produção de significado na construção identitária do Movimento dos Trabalhadores Rurais Sem Terra (MST), principalmente a partir de textos impressos, digitais e eletrônicos produzidos pelos sem-terra e por grupos que lhes dão suporte. Será feita também uma pequena análise sobre a presença dos diversos modos de produção de significado nas manifestações públicas do movimento. Outro aspecto a ser examinado é a configuração visual da webpage do MST. Mesmo com a presença de outros recursos da multimodalidade, percebe-se nela, assim como em outras produções midiáticas dos sem-terra, um intenso predomínio do modo linguístico, o que pode ser indicativo do forte apelo ao ativismo tão comum nos discursos do movimento. Essa propensão à militância e ao ativismo remete ao que Castells (1999: 24) chama de identidade de resistência, vinculada a grupos sociais em desvantagem diante da lógica da dominação e que constroem sua resistência a partir de princípios diferentes daqueles das instituições dominantes da sociedade. Entretanto, por não estar apenas defendendo interesses próprios, mas também propondo uma transformação da sociedade, o movimento se insere ainda na identidade de projeto: "quando os atores sociais, utilizando-se de qualquer tipo de material cultural ao seu alcance, constroem uma nova identidade capaz de redefinir sua posição na sociedade e, ao fazê-lo, de buscar a transformação de toda a estrutura social" (1999: 24). Embora esses dois tipos de identidade sejam muitas vezes conflitantes (mas não excludentes), com frequência podem ser também complementares. A fim de contextualizar a presente discussão, e antes de prosseguir com a análise, será apresentado a seguir um breve histórico do movimento.

A consolidação do MST como um movimento político organizado se deu em 1984 (HISTORY..., 2003), ainda no período do governo militar. O primeiro congresso do movimento, no ano seguinte, reuniu mais de 1.500 delegados representando os sem-terra de 23 estados. Mas os participantes não se limitavam aos trabalhadores rurais. Segundo Branford e Rocha (2004: 52), entre eles havia ainda parlamentares, representantes de ONGs, líderes indígenas, delegados de confederações camponesas da América Latina, líderes sindicais, bispos católicos e ministros luteranos. Além da heterogeneidade na composição dos participantes, era preocupação do movimento, desde o início, que sua luta se tornasse nacional, não selimitando aos estados do sul do país, onde o MST se originara a partir de conflitos agrários envolvendo trabalhadores rurais na década de 1970. Outro aspecto 
importante para o movimento na época de sua fundação era manter sua autonomia em relação a outros atores sociais já estabelecidos. Houve quem defendesse a atuação dos sem-terra na esfera de partidos políticos ou centrais sindicais. Para outros, deveriam ficar sob a proteção da Igreja Católica, que teve papel fundamental na fundação do movimento através da Comissão Pastoral da Terra (CPT). Logo se deram conta, entretanto, de que estariam, dessa maneira, excluindo ativistas de outras igrejas, como a luterana, que também apoiavam as causas dos sem-terra. A tese da autonomia acabou prevalecendo, mas a interação com outros atores sociais se manteve, pois muitas de suas reivindicações coincidem com as do movimento. O MST tem ainda o apoio de organizações solidárias distribuídas por catorze países em várias partes do mundo (QUIRK, 2007). Essa heterogeneidade na formação e constituição do movimento é ilustrativa da complexidade identitária do sem-terra, que é geralmente reconhecida pelo movimento. Ao mesmo tempo, porém, o próprio MST esforça-se em representar o semterra como um sujeito coletivo unitário, congregado em torno de símbolos únicos como o hino e a bandeira.

Hoje o MST tem aproximadamente 1.500 .000 membros e está presente em 23 estados do Brasil (QUIRK, 2007). Já foram oficializados cerca de 2.300 assentamentos, onde funcionam 88 cooperativas e 96 agroindústrias, além de 1.800 escolas de ensino médio e fundamental. Recentemente, foi inaugurada também a Escola Nacional Florestan Fernandes, em São Paulo, voltada para o ensino superior dos sem-terra e de outros grupos sociais menos privilegiados. A estrutura organizativa do movimento é baseada num conjunto de setores e coletivos (ABOUT..., 2006), tais como: Produção, Cooperação e Meio Ambiente; Educação e Formação Política; Gênero; Comunicação; Saúde; Direitos Humanos; Relações Internacionais; Cultura. O movimento tem duas publicações periódicas: o Jornal Sem Terra, de circulação mensal, foi fundado há 27 anos; e a Revista Sem Terra, bimestral, começou a circular há doze anos. Há ainda uma emissora de rádio virtual, a Vozes da Terra. O acesso a ela pode ser feito pela webpage do movimento, www.mst.org.br, criada em 1996 e disponível também em sete línguas estrangeiras. Em entrevista gravada, Maria Lúcia, ${ }^{1}$ integrante do setor de comunicação do movimento, explica que, enquanto o jornal é direcionado aos integrantes do movimento, a revista e a mídia virtual são

\footnotetext{
${ }^{1}$ Nome fictício. Entrevista realizada em 26 de junho de 2007 e gravada em arquivo MP3.
} 
voltadas para o público em geral. Pelo seu dinamismo, a Internet permite mais flexibilidade e rapidez na produção das notícias em comparação com os meios impressos. Segundo a entrevistada, a página serve como uma vitrine para a atuação do movimento e surgiu com o propósito de informar a população sobre questões que normalmente não são noticiadas pela grande imprensa, mais propensa a enfatizar os aspectos negativos do movimento.

\section{A MULTIMODALIDADE NAS MANIFESTAÇÕES DO MST}

Os modos de produção de significado que estão adquirindo maior grau de importância, segundo teóricos do multiletramento (THE NEW LONDON GROUP, 2000: 28), são cinco: visual, auditivo, gestual, espacial e multimodal. Este último refere-se à integração de todos os anteriores, incluindo também o tradicional modo linguístico. Cope e Kalantzis (2000b: 5) argumentam que estão em processo uma multiplicidade e integração crescentes de modos de produção de significados, "em que o textual está relacionado também com o visual, o sonoro, o espacial, o comportamental, entre outros. Isso é particularmente importante nos meio de comunicação de massa, na multimídia e na hipermídia eletrônica.". O significado seria, portanto, produzido de maneira cada vez mais multimodal.

Uma das habilidades pressupostas nas teorias de multiletramento, a espacial, é extremamente significativa para o trabalho com a terra e para a transformação pelo sem-terra de sua realidade social, aspecto de capital importância para o movimento. Knijnik (1994: 76), por exemplo, relata como no meio rural do Rio Grande do Sul os trabalhadores têm utilizado métodos populares de medição de terra que divergem dos métodos oficiais baseados na matemática acadêmica, mas que de qualquer maneira estão em estreita relação com a visão de mundo da comunidade. Além disso, o espaço do acampamento não é apenas o local do cultivo, do trabalho mecânico, mas principalmente o da convivência e dos relacionamentos pessoais e sociais. A partir daí, configura-se também o assentamento como local de resistência política e cultural. Segundo José Batista de Oliveira, integrante da direção nacional do movimento, "os assentamentos são espaços, territórios de disputa permanente" (AUGUSTO, 2008).

\footnotetext{
${ }^{2}$ A tradução de textos originalmente em língua estrangeira é de minha responsabilidade.
} 
Os vários modos de produção de significado estão presentes também na webpage do MST, uma vez que o texto escrito interage com imagens, vídeos e mensagens gravadas em áudio, disponíveis na seção "Vozes da Terra". Mesmo para o assentado que não tem acesso a computador ou Internet, as possibilidades são imensas. No seu dia a dia, ele está em contato com o modo visual na televisão ou nas mídias impressas do MST. O modo auditivo está presente nos meios de comunicação de massa. Segundo Maria Lúcia, integrante do setor de comunicação do movimento, durante o V Congresso Nacional do MST em Brasília, em 2007, foram organizadas "frentes de comunicação", como, por exemplo, a de audiovisual. Uma emissora de rádio foi montada especialmente para o evento. Há ainda as rádios comunitárias, como a Palmares $\mathrm{FM}$, instalada num assentamento no município de Parauapebas, Pará (STEDILE; BECHARA, 2008: 6). Teatro, música e dança também estão presentes na vida do sem-terra, principalmente nas manifestações (CULTURE..., 2006). A questão relativa à "produção de significados" (COPE; KALANTZIS, 2000b: 5) fica evidente ainda na utilização dos modos gestual e espacial nas manifestações e ocupações. As manifestações, por sinal, não se restringem ao MST, mas são uma tradição em movimentos políticos e sociais. Mesmo com a intensificação do ativismo digital, as manifestações públicas em espaços reais não diminuíram de intensidade. Na verdade, muitas delas adquiriram status internacional, amplificadas pelas novas mídias, como os protestos em Seattle, Estados Unidos, em 1999, contra a Organização Mundial do Comércio (DOWNING, 2003; RODRÍGUEZ, 2008). Segundo Yúdice (2004: 216), a cobertura da mídia fez os sem-terra dar mais atenção à maneira como fazem a coreografia de suas marchas e se apresentam visualmente, a fim de conseguir mais visibilidade e solidariedade. Ao lado das ocupações, as manifestações são a principal tática do MST para atingir seus objetivos. Em ambos os casos, o espaço é um fator significativo.

$\mathrm{O}$ uso do gesto sempre esteve presente em manifestações. Ações coordenadas, ou até mesmo coreografadas, são muitas vezes usadas para reforçar palavras de ordem e proporcionar um efeito de união e harmonia entre os participantes, além de dar à coletividade a sensação de um corpo homogêneo. No caso dos sem-terra, há um aspecto que se sobressai e que torna suas manifestações singulares: como o homem que aparece segurando o facão no logotipo do MST, os sem-terra empunham suas ferramentas para o alto, ao contrário do uso que fazem delas no trabalho diário. Esse contraste pode ser percebido na imagem colocada no topo da webpage do 
MST, que mostra ambos os momentos lado a lado. Numa análise semiótica de imagens, Kress e van Leeuwen (2006: 186) afirmam que, em geral, a parte superior representa o ideal, enquanto a inferior, o real. Nesse caso, pode-se argumentar que, no trabalho diário com a terra, as ferramentas enfatizam a ideia de que o sem-terra é um trabalhador e que faz bom uso da terra que conquistou. Nas manifestações, a ferramenta, voltada para o alto, simboliza o ideal de algo que ainda não foi conquistado e pelo qual o sem-terra luta. Demonstra também que esta é mais uma opção do trabalhador: a de não trabalhar, ou de estabelecer seu próprio horário de trabalho. É uma decisão sua, e não uma decisão tomada por um patrão ou pelo governo.

Em alguns casos, o gesto pode ser apenas um acessório que reforça o conteúdo veiculado verbalmente. Em outros, pode ser o principal produtor de significado, uma vez que o elemento visual pode ser mais eficaz que o linguístico. $\mathrm{O}$ uso das ferramentas e da indumentária, por exemplo, já de início indica que seus portadores são trabalhadores rurais, sem a necessidade de recorrer a palavras, tanto faladas quanto escritas. Além disso, as ferramentas adquirem significados sociais variados de acordo com o uso que os sem-terra fazem delas, o que demonstra que elas também estão inscritas em processos de representação. Em primeiro lugar, facões, enxadas e foices denotam trabalho árduo e manual e são, portanto, constituintes da identidade do sem-terra, em contraste, por exemplo, com as grandes máquinas empregadas em lavouras mecanizadas, que, numa leitura semiótica, são representantes do latifúndio e da monocultura. Nas manifestações de ruralistas e agricultores não alinhados com os sem-terra, não se veem ferramentas manuais, mas máquinas agrícolas. Não que os sem-terra não façam uso dessas máquinas em seu trabalho, o que faria supor que eles são "anacrônicos" e avessos à tecnologia, como muitas vezes eles são descritos. O trabalho mecanizado também está presente no dia a dia do sem-terra em muitos assentamentos e também é, portanto, um dos elementos que modelam sua identidade. A preferência pela ferramenta manual, por outro lado, coloca ênfase no ser humano, no trabalhador rural, enquanto a máquina assume outra simbologia, como a do capital, por exemplo. Esses aspectos são ilustrativos de como instrumentos de uso social entram em conflitos de significação e representação. A segunda característica relacionada aos significados sociais assumidos pelas ferramentas está vinculada ao fato de que, ao usá-las, o MST demonstra que o sem-terra não é apenas um trabalhador rural cuja aspiração seja tão somente dedicar-se à sua lavoura e tirar dela seu sustento, mas que, na 
verdade, é um sujeito politizado lutando para assumir um papel ativo na sociedade e, em última instância, transformá-la. Por fim, as ferramentas podem ser vistas (representadas) ainda como armas, leitura muitas vezes privilegiada pelos oponentes do movimento, ainda que, na grande maioria das vezes, as manifestações do MST tenham um caráter estritamente pacífico.

Numa manifestação, portanto, estão presentes todos os modos de produção de significado relativos ao multiletramento: o visual, o sonoro, o espacial e o gestual, além do linguístico, tanto oral quanto escrito. Os exemplos citados acima revelam a potencialidade desses modos, principalmente quando se combinam e resultam na multimodalidade. Algumas questões precisam ser levadas em conta. A presença desses modos no trabalho, manifestações e ocupações do movimento não é, em grande parte, algo natural, mas motivado. Há que se levar em conta que muitos sem-terra são provenientes do meio urbano e nunca tiveram um contato mais íntimo com a terra. A noção que eles têm de espaço (e também de comportamento, linguagem etc.) é, portanto, diferente daquela que possuem os que cresceram no meio rural. Longe de ser um problema, esse aspecto demonstra a diversidade no interior do movimento. Como consequência, há todo um processo pedagógico inscrito na rearticulação desses sujeitos para sua transformação em trabalhadores rurais, como atestam muitos dos relatos apresentados por Branford e Rocha (2004). $\mathrm{O}$ mesmo se aplica à grande maioria dos sem-terra, que passou de uma situação de assujeitamento a empregadores e autoridades para uma de resistência e/ou militância. Há ainda toda uma economia em torno da adaptação desses sujeitos à vida em coletividade: mais que pedagógico, trata-se de um processo disciplinar, tanto da mente quanto do corpo. Em todos esses casos, há uma transformação que se dá, em grande medida, a partir das noções que o sem-terra tem de sua realidade e do mundo à sua volta. Por isso, as noções de multimodalidade e multiletramento podem ser pensadas apenas em relação ao seu uso contextualizado (BRASIL, 2006).

\section{A MULTIMODALIDADE NA WEBPAGE DO MST}

A partir das manifestações, ocupações e outros atos do movimento, são produzidas narrativas por meio do texto escrito, visual ou sonoro que são veiculadas em suas mídias e alcançam pessoas no mundo todo. Há, portanto, um prolongamento do ativismo em tempo real do movimento que pode ser definido como ativismo digital. As questões que se colocam no momento 
são: o que há além desse ativismo? Que instrumentos o MST coloca à disposição do sem-terra para a transformação de sua realidade? Até que ponto as diferentes vozes que compõem o movimento estão representadas em suas mídias? É preciso salientar que a análise a seguir baseia-se primordialmente nas mídias do MST, com ênfase na autorrepresentação do movimento. Os dados, portanto, não são fruto de pesquisa etnográfica, a não ser por algumas situações de observação in loco. Outra fonte relevante é a já mencionada entrevista com Maria Lúcia, integrante do setor de comunicação do movimento.

Segundo Maria Lúcia, os meios de comunicação do MST podem ser classificados da seguinte maneira: de um lado o Jornal Sem Terra, voltado para um diálogo "com a base" (os próprios sem-terra), e de outro a Revista Sem Terra, a webpage e o Letra Viva. ${ }^{3}$ Esses três últimos teriam como objetivo dialogar "com a sociedade". No todo, essas mídias apresentam características em comum, das quais algumas podem ser problematizadas. Em primeiro lugar, nota-se que, apesar da presença de vários modos de produção de significado, o linguístico é o predominante, enquanto os outros são mais ilustrativos, usados para reforçar o conteúdo verbal. Em segundo lugar, como consequência, há um forte teor militante nas mídias do MST. A ênfase veemente no coletivo deixa pouco espaço para a representação de identidades individuais, mesmo que socialmente construídas (KRESS, 2000a: 155).

Ainda segundo Maria Lúcia, a revista, em comparação com o jornal, traz textos mais densos, acadêmicos, pois "demanda um certo conhecimento para poder ler", o que faz pressupor que o jornal apresenta uma linguagem mais identificada com a do sem-terra. Este seria, portanto, um espaço vigoroso para dar voz ao trabalhador rural, com suas especificidades culturais e identitárias. Um espaço que desse conta de toda a diversidade característica dos integrantes do movimento. Todavia, o que se vê é a mesma narrativa baseada na luta do MST contra o mundo capitalista, que dá ao movimento um ar de coesão e harmonia, mas que resulta numa homogeneização dos sem-terra. A diversidade, neste caso, parece ser maior na revista. A seção "Cultura", em particular, traz vários exemplos de manifestações culturais e artísticas não apenas de diferentes regiões do Brasil, mas também de outros países. É fundamental reconhecer que essas expressões normalmente não

${ }^{3} \mathrm{O}$ Letra Viva é um informativo em torno de um tema específico que é enviado periodicamente por $e$-mail a pessoas cadastradas. 
encontram espaço na grande mídia à qual o movimento se opõe. Ainda assim, são artigos escritos por jornalistas ou acadêmicos e, uma vez mais, a voz do sem-terra propriamente dito está apagada, mesmo que esses textos façam alusão às expressões culturais como legitimamente populares. Nessa mesma seção, o caráter visual também muda: fotos e desenhos das manifestações culturais, e de seus praticantes, contrastam com as demais ilustrações da revista, que em geral retratam as ações e manifestações do movimento e de seus parceiros. Uma importante exceção - exibida na seção "MST" da revista - é a foto de um monumento em homenagem aos mortos no que os sem-terra chamam de "Massacre de Carajás". Em 1996, 22 sem-terra foram mortos pela polícia militar em uma manifestação em Eldorado do Carajás, no Pará. O monumento, construído em 1999, mostra vários troncos de castanheiras, aparentemente queimados, colocados à beira da estrada onde aconteceram os confrontos. A sinergia com a terra e a natureza pode ser inferida pela pequena planta que brota do topo de um dos troncos sem vida, simbolizando também a persistência dos sem-terra, como quem não se deixa abater pelas adversidades. A opção pela foto do monumento abre espaço para um leque maior de interpretações, ao passo que uma foto de sem-terra em manifestação ou protesto não faria mais que reforçar o conteúdo do texto escrito.

Na webpage do movimento, apesar dos vários modos de produção de significado presentes, o linguístico também é o predominante. $\mathrm{Na}$ verdade, em comparação com as mídias impressas do movimento, pouco uso é feito de elementos visuais (ou mesmo sonoros) e de todo o potencial que a multimodalidade oferece. Isso é ainda mais evidente nas webpages internacionais. ${ }^{4}$ Como resultado, a webpage é quase que uma reprodução dos tradicionais meios de comunicação, com uma abordagem extremamente objetiva e jornalística. Vozes da Terra, a rádio virtual do MST, disponível no website, não vai muito além de transmitir reportagens faladas nos moldes dos textos escritos. Segundo Maria Lúcia, o "conteúdo" - veiculado principalmente por meio do texto escrito - é mais importante que o visual, que é visto apenas por seu valor estético. Para ela, as pessoas têm que ter fácil acesso ao conteúdo, pois é ele, e não o visual, que atrai as pessoas. "A página tem que ser bonita, mas funcional", afirma ela. A primazia do modo linguístico é descrita por Kress da seguinte maneira:

\footnotetext{
${ }^{4}$ Como já mencionado, a página está disponível em sete línguas estrangeiras: inglês, francês, espanhol, italiano, alemão, holandês e sueco.
} 
Existe uma tendência geral em se considerar a língua como um meio comunicativo e representacional totalmente adequado à expressão de qualquer coisa que queiramos expressar: que qualquer coisa que pensemos ou sintamos pode ser dita (ou escrita) através da língua. O outro lado dessa ideia é que, se alguma coisa não pode ser expressa através da língua (se tal coisa existisse), então essa coisa está, de qualquer maneira, fora do pensamento racional, fora do sentimento articulado e, portanto, não precisa ou não deveria ser dita. Essa pressuposição está ancorada no senso comum tanto popular quanto teórico; inúmeras investigações teóricas a reproduzem e a reforçam constantemente. (2000b: 193)

Rodowick (2001: 31) argumenta que a separação entre o visual e o verbal tem profundas raízes no Iluminismo do século 18. Do ponto de vista do racionalismo iluminista, o verbal era o único modo encarregado da significação e da comunicação, enquanto o visual ficava relegado exclusivamente ao campo da estética. Segundo o autor, essa fronteira entre expressão visual e verbal ainda prevalece nos dias de hoje, mas vem sendo constantemente desafiada pelas "qualidades híbridas" (p. 37) das artes cinematográficas e digitais. A excessiva importância que vem sendo dada à cultura letrada nos últimos tempos, à qual boa parte dos sem-terra não tem acesso, reflete também esse problema, o que reforça a ideia de que a intensificação da comunicação visual entre eles pode ser um fator de empoderamento. Contudo, a multimodalidade pressupõe que todos os modos de representação façam parte de um texto integrado. Segundo Kress e van Leeuwen (2006: 177), uma figura não é apenas uma "ilustração" do texto verbal, nem o texto verbal e o visual são tratados como elementos separados. Portanto, o conteúdo não está apenas no texto verbal, mas no todo. Esse todo, incluindo o visual e em alguns casos o sonoro, pode chamar a atenção de um leitor desavisado navegando pela Internet, que, segundo Manovich (2001: 78), assemelha-se a um Robinson Crusoé, "caminhando pela areia, pegando um diário de navegação, uma fruta em decomposição, um instrumento cuja finalidade ele não conhece; deixando marcas que, como hyperlinks digitais, se sucedem partindo de um objeto encontrado para outro".

O aspecto visual que mais chama a atenção na página do MST é o cabeçalho, com o logotipo e o nome do movimento. No fundo, cenas de sem-terra em manifestação ou trabalhando são esmaecidas pela cor vermelha predominante, como se vistas através de um filtro. Um filtro que, por sinal, é fornecido pelo próprio movimento e que, não por acaso, 
é vermelho. Essa é também a cor da bandeira, o ícone sem-terra mais veiculado tanto pelo movimento quanto pela mídia em geral. O cabeçalho contém ainda links para outras seções e se mantém inalterável enquanto se navega pela página. Abaixo vem a seção de notícias, que ocupa quase todo o espaço. Está dividida em duas colunas. A da esquerda, mais ampla, exibe notícias recentes e muda com mais frequência. Conforme novas notícias entram, as anteriores vão se deslocando para a parte inferior da coluna. As que estão no topo ganham mais destaque por terem fonte maior e virem acompanhadas de um texto introdutório. Nas de baixo, apenas os títulos permanecem. São todas hyperlinks para o texto integral, como a primeira página de um jornal. Os textos em geral são escritos, mas em alguns casos tem-se acesso a vídeos e fotos. A coluna da direita é menos dinâmica, com links para artigos e entrevistas que mudam com menos frequência. Tem um fundo levemente azul e os itens são separados por linhas tênues. Na parte inferior, estão os poucos ícones usados como links, que se limitam à seção "Vozes da Terra", aos periódicos do movimento e às páginas em língua estrangeira, identificadas por bandeiras dos países europeus onde se falam aquelas línguas. No geral, a fonte utilizada é Times New Roman, de cor preta na coluna da esquerda e verde na da direita. Há pouco dinamismo e pouco uso de cores e imagens; o vermelho predomina e é o único aspecto que rompe com a rigidez. Com uma certa frequência, alguma figura é posta na coluna da esquerda, ao lado de alguma das notícias em destaque. P o d e se concluir que, esteticamente, a webpage do MST é clássica, tradicional e conservadora. Isso pode estar relacionado com o tipo de usuário que o movimento procura atrair: o sujeito politizado, pouco afeito aos atrativos de cores e imagens, cujo interesse estaria voltado muito mais para a busca por informação qualificada que para o entretenimento descompromissado.

Além do visual, o sonoro também tem um forte poder de representação nas novas mídias, conforme se pode observar em um DVD produzido pela Développement et Paix (BRÉSIL..., 2007), organização católica canadense de apoio a movimentos sociais nos países menos desenvolvidos. De acordo com uma integrante dessa organização, ${ }^{5}$ o DVD, disponível em inglês e francês, foi produzido com a intenção de mostrar aos contribuintes financeiros - em geral, membros da Igreja Católica no Canadá - o que é o MST. Eles, enfim, estavam interessados em saber para que tipos de

\footnotetext{
${ }^{5}$ Em entrevista não gravada concedida ao autor deste trabalho em 14 de maio de 2008, em Winnipeg, Canadá.
} 
organização estavam contribuindo. O DVD, então, é uma coletânea de fotos dos sem-terra em seu dia a dia e em manifestações, entremeadas com informações escritas sobre o movimento, na maioria enfatizando dados numéricos. A música de fundo é a canção "Nge kuenda", do grupo brasileiro Tupi Nagô. A união da cultura do nativo brasileiro com a do negro africano no título do grupo sugere um certo hibridismo cultural. Mas nessa canção específica, a letra não é em português. Assim como o ritmo se assemelha muito ao de certos estilos de música africana, a língua provavelmente é também originária de alguma comunidade africana. Pode-se argumentar, por um lado, que a escolha dessa canção procura contemplar a cultura popular brasileira identificada com o MST, apesar de pouco ter de rural. Por outro lado, o estilo africano pode ser mais eficaz para que ouvintes de países mais desenvolvidos relacionem a causa em questão a países menos desenvolvidos, o que dificilmente aconteceria com algum estilo de música caipira brasileira, não tão bem conhecido pelos canadenses. Essa possibilidade sugere uma homogeneização de sentido em muitas das produções audiovisuais de países do Hemisfério Norte ocidental. Uma outra situação, bastante comum em filmes que retratam países latinoamericanos, é caracterizada pela presença de ritmos como bolero e salsa para expressar sensualidade, mesmo quando a referência é o Brasil, onde esses ritmos são pouco comuns. Outro exemplo do poder de significação do modo sonoro nas mídias está nos vídeos do MST, como o Lutar sempre! (2007a, 2007b, 2007c), nos quais podem ser ouvidos tanto estilos de música popular brasileira quanto canções de protesto típicas da década de 1970. Ao mesmo tempo em que se reafirma a identidade rural popular do sem-terra, enfatiza-se também o caráter de luta do movimento e sua conexão com povos principalmente de países hispano-americanos, já que muitas dessas canções são provenientes desses países. Nesse caso, não apenas as canções, mas a própria língua espanhola tem sua participação na construção da identidade do sem-terra.

\section{CRÍTICA E PROJETO}

Para Maria Lúcia, entretanto, é a mensagem linguística que deve atrair o leitor, pois ali, principalmente na página do MST, ele teoricamente vai se deparar com abordagens incomuns, pouco prováveis de serem encontradas nos meios de comunicação a que as pessoas estão normalmente expostas, "ressignificando" assim o movimento. A escolha das fotos é usada em geral para reforçar a identidade de resistência do sem-terra. A entrevistada 
compara o tratamento dado a uma mesma notícia por uma agência de notícias e pelo MST. Ela se refere à webpage, mas essa visão pode se estender também às mídias impressas do movimento, principalmente porque nelas há uma presença maior de fotos. No caso de uma notícia sobre a transposição do Rio São Francisco, exemplifica ela, uma agência normalmente colocaria uma foto de um ministro falando, ao passo que o MST mostraria uma foto de pessoas manifestando-se contra a transposição. Numa notícia sobre transgênicos, uma agência exibiria a foto de uma espiga de milho, enquanto que o MST, a de pessoas protestando. Maria Lúcia explica: "o interessante pra gente é mostrar as pessoas protestando contra o milho transgênico, mesmo que a matéria não esteja falando do protesto e que o protesto tenha sido um ano atrás". Ainda que, aparentemente, as fotos possam estar apenas servindo como ilustração para o texto escrito, a presença delas por si só oferece uma outra leitura, evidente na comparação: não há como afirmar neutralidade nos meios de comunicação. A diferença é que as agências de notícias tendem a proclamar uma postura neutra, enquanto o MST procura ser mais claro quanto à sua posição. Em jogo estão questões de poder e ideologia:

consideramos qualquer tipo de imagem como totalmente pertencente à esfera das realizações e instanciações da ideologia, como um meio - sempre - para a articulação de posições ideológicas. A questão é que nem o poder nem o seu uso desapareceram. Simplesmente ficou mais difícil seguir seu traçado e localizálo. Nesse contexto há uma necessidade absoluta, em termos democráticos, de tornar disponíveis os meios para se entender as articulações do poder em qualquer lugar, em qualquer forma. (KRESS; VAN LEEUWEN, 2006: 14)

Apesar do pouco acesso à Internet, o sem-terra, segundo Maria Lúcia, identifica-se com a página ao se tornar notícia. Mas, uma vez mais, é uma identidade forjada majoritariamente na militância, portanto uma identidade de resistência na definição de Castells (1999). Uma militância nem sempre correspondente à realidade. A fala da entrevistada permite a interpretação de que uma mesma foto seja colocada junto de matérias distintas, o que demonstra o potencial de fabricação do real na mídia, incluindo a do MST. Para Maria Lúcia, o importante é dar uma visão alternativa aos grandes meios de comunicação, uma outra perspectiva ao leitor: "isso é democratizar a comunicação". Os exemplos acima mostram como o MST, em suas mídias, constrói sua identidade a partir da narrativa do Outro, como uma alternativa. Em destaque está sempre o coletivo, em contraposição aos seus oponentes 
históricos, com pouca atenção para as diferenças individuais e conflituosas no interior do movimento. Não que o MST deva ignorar a existência de seus adversários, pois muito de sua identidade é construída, em maior ou menor grau, a partir das relações de antagonismo. Um outro exemplo dessa característica pode ser extraído do vídeo Lutar sempre!, produzido pela Brigada de Audiovisual da Via Campesina e filmado durante o $5^{\circ}$ Congresso Nacional do MST, em 2007 (LUTAR..., 2007a, 2007b, 2007c). A matéria publicada sobre o vídeo na Revista Sem Terra (GOMES; CANOVA, 2007: 38) afirma que "os Sem Terra saem da condição de espectadores para entrar em cena como narradores de sua própria história", enfatizando que os protagonistas são todos os participantes do congresso e que "os trabalhadores são os únicos que têm o direito de contar sua própria experiência". Essas afirmações podem causar a expectativa de que se vai ver e ouvir trabalhadores rurais narrando sua "própria experiência" e dando uma amostra de toda a diversidade existente no MST.

Como a própria matéria da Revista Sem Terra afirma, a realização do vídeo esteve a cargo de "diversos militantes, dos mais distintos estados e organizações sociais” (GOMES; CANOVA, 2007: 39). Aqui já não se fala mais em trabalhadores rurais. Ao se assistir ao vídeo, percebe-se que esse é o tom dominante: diversos militantes reafirmando seu compromisso na luta do MST contra seus inimigos históricos. Com algumas exceções - em alguns momentos, podem-se ouvir os sem-terra cantando, declamando poesia ou apresentando receitas de comida -, a maior parte do filme dedica-se a enfatizar o caráter ativista do movimento como um todo. Os realizadores do vídeo preocupam-se em não ser imparciais, pois, como militantes, "toma[m] partido, ao apresentar e defender seus argumentos políticos" (GOMES; CANOVA, 2007:39). A questão é que as mídias do MST em geral esforçam-se em tornar sua posição a mais clara possível, numa espécie de excesso pedagógico, deixando pouco espaço para interpretações alternativas. Afinal, é possível não ser imparcial e defender uma visão de mundo sem necessariamente recorrer a narrativas pedagógicas e engajadas, ou ao "linguajar engessado" de certos meios de comunicação "progressistas", no dizer de Downing (2003: 284). ${ }^{6} \mathrm{O}$ autor fornece um bom exemplo de como as novas mídias podem ser utilizadas para a construção de identidade de um grupo social minoritário sem precisar recorrer a narrativas engajadas.

6 "Certain woodenly worded progressive media." 
Ele cita (2003: 285) o trabalho de Clemencia Rodríguez, uma pesquisadora colombiana que investiga a maneira como as mulheres de um bairro pobre de Bogotá desenvolveram "um senso significativamente novo de autoestima e autoafirmação" ao participar na produção de vídeos sobre seu bairro. Dessa análise, surgiu o termo citizens' media (RODRÍGUEZ, 2008): "em vez de definir as mídias alternativas como aquilo-que-não-é-mídiapadrão, nós as definimos em termos dos processos transformativos que elas proporcionam aos participantes e suas comunidades". São processos de mudança que se desenvolvem entre os participantes da produção midiática, contribuindo para a construção de sua cidadania. Assim, em vez de definir uma comunidade pelo seu Outro, a mídia cidadã procura romper com definições binárias e essencialistas de poder, concentrandose na "transformação metamórfica experimentada pelos seus produtores e participantes" (CITIZENS...., 2008). A identidade resultante desse processo pode ser inscrita na concepção de identidade de projeto de Castells (1999: 24), já que redefine a posição desses participantes na sociedade, tornando possível também a transformação de toda a estrutura social.

A narrativa visual e sonora do vídeo Lutar sempre!, por sua vez, comporta umainterpretaçãomaisflexível. Osprópriosprodutoresadmitem: "utilizamos sem qualquer preconceito ou hierarquização distintos materiais imagéticos e sonoros, combinando-os de diversas formas" (GOMES; CANOVA, 2007: 39). As imagens e os sons, libertos do discurso linguístico, em muitos momentos carregam um universo semântico diverso, testemunhando a riqueza e a diversidade características dos sem-terra e distante da narrativa épica da luta travada com seus inimigos históricos. Segundo Kress e van Leeuwen (2006: 18), "o componente visual de um texto é uma mensagem organizada e estruturada independentemente, em conexão com o texto verbal, mas de maneira nenhuma dependente dele - e vice-versa". Na verdade, para eles (p. 41), os diferentes modos de representação constituem diferentes potenciais de formação de subjetividades, mas não devem ser vistos como atividades autônomas. Monte Mór (2006: 133), por sua vez, concebe a multimodalidade como "a aproximação ou justaposição de diferentes modos de comunicação [...] para criar um efeito específico ainda não disponível em qualquer um dos modos específicos em questão". Para Barthes (1977: 38), toda imagem é polissêmica e implica "uma corrente flutuante" de significados, dando ao leitor a possibilidade de escolher alguns e ignorar outros. Entretanto, essa polissemia sempre se traduz como uma disfunção e, portanto, em toda sociedade, segundo o autor, várias 
técnicas são desenvolvidas para fixar (grifo no original) essa corrente de significados; a "mensagem linguística" é uma delas. Consequentemente, o texto linguístico tem um valor repressivo (1977: 40) e revela a ideologia e o grau de moralidade que informam uma sociedade.

As místicas que o MST apresenta em seus encontros podem ser consideradas uma instância em que o modo linguístico cede lugar para outras modalidades. São também eventos em que narrativas míticas e simbólicas substituem as narrativas lineares e teleológicas identificadas, em grande parte, com o discurso linguístico do movimento. Permitem, assim, maior liberdade de interpretação e identificação. As místicas são também multimodais, pois são apresentações que mesclam gêneros diversos como dança, teatro e música, utilizando-se, portanto, dos modos visual, gestual, espacial e sonoro. Elas são, normalmente, apresentadas em eventos-chave como congressos e encontros. Em entrevistas ao autor deste trabalho, duas representantes da Coordenação Nacional do MST, Marina dos Santos e Luciene, ${ }^{7}$ salientaram a importância simbólica da mística. Para Luciene, ela expressa o "lado espiritual" do movimento. Minimizando o papel da palavra nesses eventos, ela completa: "a mística, a gente não explica, a gente sente". Nem por isso, a política perde sua importância. Segundo Marina dos Santos, "a mística tem a ver com o projeto de transformação da realidade que operamos. A celebração tem a ver com a estetização e politização da experiência de lutas, da memória dos combates, da evocação dos símbolos e valores que movem nossa organização." É comum nessas celebrações, a formação de círculos ou espirais, que reforça seu caráter mítico ou pagão, em contraste com a feição teleológica e militante das marchas.

As noções de Projeto (Design) e Crítica (Critique) (KRESS, 2000a; COPE; KALANTZIS, 2000c; THE NEW LONDON GROUP, 2000) podem ser úteis para uma discussão mais aprofundada das questões acima. Elas se inserem nas discussões sobre multiletramento e multimodalidade e proporcionam elementos para a análise da construção da identidade a partir dos recursos disponíveis a um grupo social num determinado momento. Kress (2000a: 160) sugere que a noção de Projeto pressupõe uma competência máxima no uso desses recursos - inclusive de seus potenciais comunicativos, políticos e ideológicos - e requer uma reelaboração que venha a satisfazer

\footnotetext{
${ }^{7}$ Marina dos Santos respondeu ao questionário por escrito em e-mail enviado ao autor deste trabalho em 11 de novembro de 2007. A entrevista com Luciene (nome fictício) foi gravada em 18 de setembro de 2007 em arquivo MP3.
} 
as intenções do sujeito no processo de modelar o ambiente sociocultural. "O Projeto modela o futuro por meio do emprego deliberado de recursos representacionais e em função dos interesses de quem projeta." A ideia de Crítica, por outro lado, lança um olhar sobre o presente em função de produções passadas, de modo que a tarefa do crítico seria conduzir sua análise com base no Projeto de outros. Para Kress, essa tarefa está associada a configurações sociais e períodos históricos em que certos indivíduos e grupos estabelecem uma agenda à qual os demais se sujeitam ou se opõem. Cope e Kalantzis associam a noção de Projeto ao processo de produção de significado, com importantes implicações culturais:

O foco recai, não na estabilidade e na regularidade, mas na mudança e na transformação. Os indivíduos têm à sua disposição um conjunto complexo de recursos representacionais, nunca de uma cultura apenas, mas das muitas culturas que constituem sua experiência vivida, das muitas camadas de sua identidade e das múltiplas dimensões de seu ser. A abrangência, a complexidade e a riqueza dos recursos para a produção de significado disponíveis são tais que a representação nunca é apenas uma questão de reprodução. É, na verdade, uma questão de transformação e de reconstrução do significado de tal maneira que sempre agregue alguma coisa ao conjunto de recursos representacionais disponíveis. (2000c: 204)

\section{CONCLUSÃO}

As noções de Crítica e Projeto podem enriquecer as definições de identidade de Castells (1999) anteriormente citadas. Assim como a noção de Crítica, a identidade de resistência interpreta o presente com base em produções passadas, daí a ênfase na tradição. Da mesma forma, a identidade se define a partir do outro. A identidade de projeto, por outro lado, bem como a própria noção de Projeto, desenha o futuro a partir do uso dos recursos disponíveis ao grupo no momento presente, mas historicamente situado. A transformação da sociedade que o MST propõe se faz no cotidiano e depende crucialmente do uso extensivo que o sem-terra faz dos recursos à sua disposição. Entre esses recursos, podem-se incluir os diversos modos de produção de significado inseridos na multimodalidade e as diversas mídias às quais o movimento tem acesso.

Quanto a essas mídias utilizadas pelo MST, o que aparentemente falta nelas é o ponto de vista dos trabalhadores rurais como indivíduos, sua própria expressão cultural baseada na experiência e visão de mundo de cada um dos variados grupos que compõem o movimento, marcados por 
diferenças étnicas, geográficas, religiosas e linguísticas, entre outras. $\mathrm{O}$ integrante do movimento aparentemente não tem voz própria, a não ser que ela esteja em consonância com a ideologia do grupo dominante. Essa ideologia tem sido eficaz para transformar o trabalhador rural em militante, utilizando-se mesmo do seu próprio conhecimento de mundo e de variados modos de produção de significado presentes no seu cotidiano, conforme já se discutiu. Outra coisa, porém, seria utilizar esse conhecimento e esses modos para, não apenas reafirmar identidades, mas também produzir novas identidades, sociais, políticas e culturais, libertas do fardo pesado do ativismo. Não se trata de afirmar que o que está em processo seja um caso de autoritarismo, mas o de uma autoridade monológica, em que uma voz hegemônica obscurece o dialogismo conflituoso das demais vozes. São elas que têm o poder de construir o popular, tão caro ao MST. Apagadas essa vozes, o popular se essencializa e perde sua dinamicidade, pois muito do ativismo dirigido do movimento desconsidera a heterogeneidade de seus membros. No vídeo Lutar sempre! (2007c), um militante do MST apresenta duas possibilidades de futuro para o movimento: desaparecer com o ciclo atual ou "ajudar a dar início a um novo ciclo de luta social". É nesse segundo contexto, em que o MST seria o protagonista de um novo momento social no Brasil, que a identidade de projeto e a noção de Projeto poderiam ser mais úteis, já que a resistência e a crítica não seriam suficientes.

\section{REFERÊNCIAS BIBLIOGRÁFICAS}

ABOUT the MST. Disponível em: <http://www.mstbrazil.org/?q=book/ print/16>. Acesso em: 23 dez. 2006.

AUGUSTO, Danilo. Assentamento, espaço de organização. 30 maio 2008. Disponível em: <http://www.mst.org.br/mst/pagina.php?cd=5419>. Acesso em: 31 maio 2008.

BARTHES, Roland. Image, Music, Text. Trad. Stephen Heath. New York: Hill and Wang, 1977.

BRANFORD, Sue; ROCHA, Jan. Rompendo a cerca: a história do MST. Trad. Rubens Galves Merino. São Paulo: Casa Amarela, 2004.

BRASIL. Secretaria de Educação Básica. Orientações Curriculares para o Ensino Médio: linguagens, códigos e suas tecnologias. Brasília: MEC/ SEB, 2006. v. 1, p. 85-124. 
BRÉSIL: Mouvement des Paysans Sans Terre (MST). Realização de Carême de Partage / Développement et Paix. 2007. 1 DVD (4 min 48 s).

CASTELLS, Manuel. O poder da identidade. Trad. Klauss Brandini Gerhardt. São Paulo: Paz e Terra, 1999.

CITIZENS' media. In: WIKIPEDIA. Disponível em: <http:// em.wikipedia.org/wiki/Citizens\%27_media>. Acesso em: 31 jul. 2008.

COPE, Bill; KALANTZIS, Mary (Ed.). Multiliteracies: Literacy Learning and the Design of Social Futures. London: Routledge, 2000a.

COPE, Bill; KALANTZIS, Mary. Design for Social Futures. In: COPE, Bill; KALANTZIS, Mary (Ed.). Multiliteracies: Literacy Learning and the Design of Social Futures. London: Routledge, 2000c. p. 203-234.

COPE, Bill; KALANTZIS, Mary. Introduction: Multiliteracies: the Beginnings of an Idea. In: COPE, Bill; KALANTZIS, Mary (Ed.). Multiliteracies: Literacy Learning and the Design of Social Futures. London: Routledge, 2000b. p. 3-8.

CULTURE collective. Disponível em: <http://www.mstbrazil. org/?q=book/print/16>. Acesso em: 23 dez. 2006.

DOWNING, John. Radical media and globalization. In: ARTZ, Lee; KAMALIPOUR, Yahya R. (Ed.). The Globalization of Corporate Media Hegemony. Albany, NY: SUNY Press, 2003. p. 283-293.

GOMES, Thalles; CANOVA, Felipe. Em cartaz, Lutar Sempre! Revista Sem Terra, São Paulo, n. 42, p. 38-39, nov.-dez. 2007.

HISTORY of the MST. 12 fev. 2003. Disponível em: <http://www. mstbrazil.org/?q=book/print/16>. Acesso em: 23 dez. 2006.

KNIJNIK, Gelsa. Intelectuais, movimentos sociais e educação. In: VEIGA-NETO, Alfredo José da (Org.). Crítica pós-estruturalista e educação. Porto Alegre: Sulina, 1994. p. 57-82.

KRESS, Gunther. Design and Transformation: New Theories of Meaning. In: COPE, Bill; KALANTZIS, Mary (Ed.). Multiliteracies: Literacy Learning and the Design of Social Futures. London: Routledge, 2000a. p. 153-161. 
KRESS, Gunther. Multimodality. In: COPE, Bill; KALANTZIS, Mary (Ed.). Multiliteracies: Literacy Learning and the Design of Social Futures. London: Routledge, 2000b. p. 182-202.

KRESS, Gunther; VAN LEEUWEN, Theo. Reading Images: the Grammar of Visual Design. 2. ed. Abingdon: Routledge, 2006.

LUTAR sempre! $5^{\circ}$ Congresso Nacional do MST. Parte 1 (9 min 59 s). Produção da Brigada de Audiovisual da Via Campesina. Guararema, SP, set. 2007a. Disponível em: <http://www.youtube.com/ watch?v=BRDFd2c3eTo $>$. Acesso em: 10 jul. 2008.

LUTAR sempre! 5o Congresso Nacional do MST. Parte 2 (9 min 59 s). Produção da Brigada de Audiovisual da Via Campesina. Guararema, SP, set. 2007b. Disponível em: <http://www.youtube.com/ watch?v=kigmWJxiw8c $>$. Acesso em: 10 jul. 2008.

LUTAR sempre! $5^{\circ}$ Congresso Nacional do MST. Parte 3 (9 min 55 s). Produção da Brigada de Audiovisual da Via Campesina. Guararema, SP, set. 2007c. Disponível em: <http://www.youtube.com/ watch?v=hmk37OvhY4E $>$. Acesso em: 10 jul. 2008.

MANOVICH, Lev. The Language of New Media. Cambridge, Mass.: MIT Press, 2001.

MENEZES DE SOUZA, Lynn Mario T. The Ecology of Writing among the Kashinawá: Indigenous Multimodality in Brazil. In: CANAGARAJAH, A. Suresh (Ed.). Reclaiming the Local in Language Policy and Practice. Mahwah: Lawrence Erlbaum Associates, 2005. p. 73-95.

MONTE MÓR, Walkyria. Reading Dogville in Brazil: Image, Language and Critical Literacy. Language and Intercultural Communication, v. 6, n. 2, p. 124-135, 2006.

QUIRK, Patrick W. How to be a Good Friend (When You are 4,000 Miles Away). 24 set. 2007. Disponível em: <http://www.mstbrazil.org/? q=quirkonfmstsolidarityefforts $>$. Acesso em: 1 out. 2007.

RODOWICK, D.N. Reading the Figural, or, Philosophy after the New Media. Durham: Duke University Press, 2001. 
RODRÍGUEZ, Clemencia. The Renaissance of Citizens' Media. Disponível em: <http://www.wacc.org.uk/de/layout/set/print/content/ view/full/416>. Acesso em: 31 jul. 2008.

STEDILE, Miguel; BECHARA, Cássia. Rádios Sem Terra não pedem licença para transmitir. Jornal Sem Terra, São Paulo, n. 279, p. 6, jan. 2008.

THE NEW LONDON GROUP. A Pedagogy of Multiliteracies: Designing Social Futures. In: COPE, Bill; KALANTZIS, Mary (Ed.). Multiliteracies: Literacy Learning and the Design of Social Futures. London: Routledge, 2000. p. 9-37.

YÚDICE, George. A conveniência da cultura: usos da cultura na era global. Trad. Marie-Anne Kremer. Belo Horizonte: Editora UFMG, 2004. 